\title{
REVIEW \\ Frequency and age effects of secondary health conditions in individuals with spinal cord injury: a scoping review
}

\author{
MP Jensen, AR Truitt, KG Schomer, KM Yorkston, C Baylor and IR Molton
}

\begin{abstract}
Study design: Scoping review.
Objectives: To gain a better understanding of the prevalence, course and association with age of secondary health conditions in individuals with spinal cord injury (SCI).

Setting: Seattle, Washington, USA.

Methods: We performed searches of electronic databases for studies published from 1986-2011 that provided information regarding the prevalence, course or associations with age and duration of secondary health conditions in individuals with SCl.

Results: Ninety-two studies were included. The findings indicate that: (1) individuals with SCl experience a number of secondary health conditions, many of which occur at a higher rate in those with $\mathrm{SCl}$ than the normative population; (2) the most common conditions or symptoms are pain, bowel and bladder regulation problems, muscle spasms, fatigue, esophageal symptom and osteoporosis; (3) a number of conditions, including cardiovascular disease, diabetes, bone mineral density loss, fatigue and respiratory complications or infections, occur with higher frequency in older individuals or those with longer $\mathrm{SCl}$ duration, relative to younger individuals or those with shorter SCl duration; and (4) there is a marked lack of longitudinal research examining the natural course of health conditions in individuals aging with $\mathrm{SCl}$.

Conclusions: The findings support the conclusion that individuals with $\mathrm{SCl}$ show signs of 'premature aging' in different organ systems. Longitudinal research is needed to understand when problems are most likely to emerge, and to develop and test the efficacy of interventions to prevent these health conditions and their negative impact.
\end{abstract}

Spinal Cord (2013) 51, 882-892; doi:10.1038/sc.2013.112; published online 15 October 2013

Keywords: spinal cord injury; secondary conditions; aging; pain; pressure ulcer; depression

\section{INTRODUCTION}

Research supports the conclusion that individuals with spinal cord injury (SCI) develop and experience a number of secondary health conditions as a result of having a SCI. ${ }^{1-3}$ The Institute of Medicine defines secondary condition as, 'a condition that is causally related to a disabling condition (that is, occurs as the result of a primary disabling condition) and that can either be a pathology, an impairment, a functional limitation or an additional disability (p.214). ${ }^{4}$ In addition, clinicians and researchers have noted that many individuals with physical disabilities_-including individuals with SCI-show evidence of earlier onset of some health conditions usually associated with aging (for example, diabetes and cardiovascular disease), as well as a steeper slope with respect to the increase in severity or frequency of a number of health conditions in individuals with SCI relative to nondisabled age-matched peers. This pattern is often referred to in the literature as 'premature aging. ${ }^{2,5-7}$

However, although there are a number of important reviews of research on of health conditions in individuals aging with SCI, previous reviews have been either systematic reviews focused on the specific questions regarding evidence for 'premature aging' ${ }^{2}$ or narrative reviews focused on evidence regarding general bodily systems thought to be influenced by aging. ${ }^{8-11}$ To our knowledge, there is no review that has summarized the state of knowledge regarding the overall frequency and course of secondary health conditions in individuals with SCI, and the associations of each of these conditions with age and time with SCI (duration). Such a review would be useful for (1) knowing when, following a SCI, these conditions are most likely to emerge and if they are likely to worsen, resolve or remain stable over time; (2) identifying the conditions that might be the most common and important to patients in order to select those that should be the primary targets of treatment for enhancing community participation and quality of life; and (3) identifying knowledge gaps with respect to the incidence, course and impact of these conditions. The purpose of this scoping review is to better understand what is known regarding secondary health conditions in individuals with SCI, focusing on the prevalence, course, association with age and duration, as well as comparison with nondisabled samples.

\section{MATERIALS AND METHODS}

\section{Search criteria}

A scoping review is a technique to 'map' an area of relevant literature that provides comprehensive coverage but extracts a limited about of information from published studies. ${ }^{12}$ A scoping review differs from a systematic review in two important ways. Systematic reviews usually focus on a specific and welldefined question. On the other hand, scoping reviews address broader topics. 
Second, systematic reviews tend to include a relatively narrow range of highquality studies; whereas, scoping reviews tend not to assess the quality of included studies. Thus, systematic reviews tend to provide more definitive answers to very specific questions, while scoping reviews tend to provide a broader range of information that is less definitive. In this way, scoping reviews can be more useful than systematic reviews for identifying trends and areas in need of future more focused study.

This review extracted information related to (1) the prevalence of secondary health conditions, (2) associations between the prevalence or severity of the conditions and both age and SCI duration and (3) the time course of the conditions. We also limited the search to information about secondary conditions that emerged 1 or more years following the injury. This limitation identifies chronic conditions that are associated with having a SCI, but that are not necessarily related to conditions associated with the original injury that may resolve in the first year. We searched for peer-reviewed studies in PubMed, CINAHL and PsycINFO, using 76 specific search terms to identify articles that might include information about secondary conditions (the list of search terms used is available from the corresponding author), searching for each condition independently. We restricted the search to articles published in English between 1986 and 2011 and that included information about human adults ( $>18$ years of age) with SCI. This initial approach identified 2456 articles.

\section{Criteria and methods for inclusion}

Two reviewers screened the abstracts of the 2456 articles identified to find studies published in peer-reviewed journals that met the following inclusion criteria:

1. The primary purpose of the article addressed the prevalence, incidence, frequency or course of a secondary health condition, or association of the condition with age or SCI duration.

2. The primary focus of the article was on a secondary condition or conditions occurring 1 or more years post injury.

3. The sample size of study participants with SCI was greater than 5 , and the results for study participants with SCI had to be reported separately.

Any study that did not meet these criteria was excluded from further review. If the reviewers could not make a determination about inclusion, then data from the article extracted for further consideration. Based upon these criteria, 191 empirical studies were identified and data from these articles were extracted for the review.

\section{Data extraction and outcome measures}

The data extracted from the full-text articles included information about the research design, sample demographics, domains measured and any findings regarding the frequency or prevalence, severity, time course, and/or age and duration effects of a health condition. We compiled the information in a Microsoft Access database specifically designed for this project. An additional reviewer confirmed the accuracy of extracted data. By consensus of the authors, we excluded an additional 99 articles, where the full-text did not provide sufficient details about the prevalence, course or association of health conditions with age or duration. Thus, the total number of included articles is 92 .

\section{RESULTS}

\section{Prevalence and importance}

Table 1 summarizes the key findings from the 92 articles regarding prevalence of specific secondary health conditions in adults with SCI. Table 2 summarizes key findings regarding the relative frequency or importance of secondary health in studies where multiple conditions were examined in the same sample (which makes direct comparisons in relative frequency and importance possible).

The most common conditions or symptoms (often reported with a $50 \%$ or more prevalence; see Tables 1 and 2) are pain, bowel and bladder regulation problems, muscle spasms, fatigue, heart burn and osteoporosis. Other common problems (often reported with a
25-50\% prevalence) include pressure ulcers, obesity, excessive sweating, depression, cardiovascular problems, bone fractures/falls, problems with sexual activity, intermittent dysphagia and dental/oral problems. The least frequent conditions studied-many of which are still serious health conditions when they occur-include diabetes, respiratory problems, including respiratory infections and shortness of breath, heterotopic ossification, sleep problems including obstructive sleep apnea, contractures, low blood pressure, autonomic dysreflexia and thrombosis. People with SCI reported bowel and bladder regulation problems, spasms, pain and problems with sexual activity as most important (see Table 2). The most common secondary conditions that led to hospitalizations are urinary complications, pressure sores, respiratory problems, contractures, bowel complications, pain and fractures.

\section{Age and duration effects}

A number of studies examined the concurrent associations between chronological age or time since injury and the frequency or severity of the health conditions studied. Although age and SCI duration are not the same construct, they are related; depending on a person's age at injury, SCI duration and chronological age can be strongly associated. Because of this association, when one of these time-related variables is not controlled for in an analysis - which is the case in almost all of the studies reviewed-it is not possible to know for certain if a significant effect is due to chronological age or duration of SCI. ${ }^{13}$ Still, if age or duration evidence significant associations with the prevalence of the condition, they may be considered important risk factors, even if the presence of a significant association cannot be used to prove that a causal relationship exists. As a corollary, the lack of a significant association can be used as evidence that a causal relationship between age or duration and condition prevalence is unlikely.

Seven consistent findings were identified in studies where the associations were examined in two or more studies. In adults with SCI: (1) bladder problems were not found to be associated with duration; (2) spasms were not associated with duration; (3) cardiovascular disease is more prevalent in older individuals; (4) diabetes was more prevalent in older individuals; (5) bone mineral density (BMD) loss was higher in both older individuals and in individuals with longer duration; (6) older individuals reported more fatigue; and (7) respiratory complications/infections were more prevalent in older individuals.

There were a fair number of conditions where an age or duration effect was examined in only one study, making it difficult to draw conclusions regarding the consistency of these effects. Significant associations were found for age with respect to fecal incontinence (older individuals report more fecal incontinence), body mass index (older individuals report higher BMI) and prevalence of obstructive sleep apnea (obstructive sleep apnea is more prevalent in older individuals). Duration was found to be significantly associated with depression (negative association), fatigue (older at injury associated with more fatigue), contractures (longer duration associated with more contractures) and falls (shorter duration associated with more falls). Non-significant effects were found for age and thrombosis, and non-significant effects were found for duration and constipation.

Nine conditions were identified where a significant association was found in some studies with age or duration, and non-significant association in others. When significant, positive associations (older age or more duration) were found for chronic pain, pressure ulcers, bladder problems, autonomic dysreflexia, spasms, fecal incontinence and heterotopic ossification. Significant negative associations (younger age associated with higher frequency or severity) were 
Table 1 Key findings concerning frequency, age, and duration effects, course, and frequency or severity relative to normative values or samples of secondary health conditions in individuals with spinal cord injury

\begin{tabular}{|c|c|c|c|c|c|}
\hline Condition & Articles (no.) & Publication years & $\begin{array}{c}\text { Sample size } \\
\text { (range) }\end{array}$ & Prevalence & Summary of key findings \\
\hline Pain & 34 & 1989-2011 & $47-2433$ & $\begin{array}{l}\text { Overall pain rate: } 31-84 \% \text { 9,37,39-57 } \\
\text { Severe pain: } 32-53 \% 40,43,47,51 \\
\text { Musculoskeletal pain: } 40-59 \% 40,49,55 \\
\text { Neuropathic pain: } 46 \% 50 \\
\text { Nociceptive pain: } 23 \% 50 \\
\text { Pain relative to injury level } \\
\text { Above: } 14-30 \% 43,50 \\
\text { At: } 11-41 \% 40,43,49,55 \\
\text { Below: } 28-76 \% 40,43,49,50,55 \\
\text { Visceral pain: } 5-15 \% 40,55 \\
\text { Abdominal pain: } 14-31 \% 40,58,59 \\
\text { Hand pain: } 22-34 \% 60 \\
\text { Back pain: } 23-71 \% 60,61 \\
\text { Shoulder/arm pain: } 42-81 \% 62-65\end{array}$ & $\begin{array}{l}\text { Age: greater age is sometimes assoc w/more } \\
\text { pain } 40,47,49,55,65,66 \text { and sometimes } \\
\text { not. }{ }^{43,56,63,67} \\
\text { Duration: duration assoc w/more hip pain, } 66 \\
\text { but not with pain in general or shoulder } \\
\text { pain; }{ }^{48,56,63} \text { one study found a U-shaped } \\
\text { curve, with more arm pain }<5 \text { years and }>20 \\
\text { years after injury and less pain } 5-19 \text { years } \\
\text { after injury }{ }^{65} \\
\text { Course: pain tends to develop months or years } \\
\text { after injury; }{ }^{36,40,45,47,50,55,66,68} \text { once pain } \\
\text { develops, it tends to remain stable, }{ }^{40,48} \text { except } \\
\text { for (1) shoulder pain, which shows a tendency } \\
\text { to increase over time, }{ }^{14,66} \text { and (2) leg pain, } \\
\text { which demonstrated a decrease over time in } \\
\text { one study. }{ }^{6}{ }^{6}\end{array}$ \\
\hline
\end{tabular}

Skin problems including pressure ulcers (PUs)
18

$$
\text { 1986-2010 }
$$$$
21-3361
$$

Current PUs:

$14-48 \% 9,39,41,52,57,63,69,70$

PUs at first admission to $\mathrm{SCl}$ unit: $27-$ $42 \% 67,71-73$

PUs between injury and $d / c$ from first admission to $\mathrm{SCl}$ unit: $56 \%{ }^{71}$

PUs in the last 12 months: $30-46 \% 11,49,70,74$

Skin problems in the last 5 years: $33 \%{ }^{37}$
Depression

Bladder problems including urinary tract infections (UTIs), urinary incontinence (UC) and bladder cancer
13

$1995-2011$

$64-3678$

\section{7-2010}

$11-43,561$
Current probable major depressive disorder (based on measure score):

$10-59 \%^{76-80}$

Current moderate depression (based on measure score): $23-38 \% 81,82$

Current moderate severe or severe depression (based on measure score): $9 \%^{81}$ Current suicidal ideation: $15 \%^{81}$ Depression recorded from medical record during initial rehabilitation: $14 \% 83$

Self-report of depression in the previous 12 months: $22 \%{ }^{37}$

Of all encounters in a VA system, at least 1 encounter coded as addressing a depression diagnosis: $22 \%{ }^{84}$

UTIs last year: $46-48 \%^{37,49}$

UC sometimes: $37 \% 57$

UC often: $19 \% 57$

UC last year: $38 \% 49$

Upper UT deterioration: $72 \% 85$

$1+$ UTIs in previous $3-4$ years: $48-54 \%{ }^{75}$

Bladder abnormalities: $18 \% 86$

Bladder wall thickening: $11 \%$

Cystitis: $3 \%$

Bladder stone: $2 \%$

Bladder wall trabeculation: $2 \%$

Current UTI: $34 \%{ }^{41}$

Rate of bladder cancer: $0.003-0.11 \% 17,18$

Age: rate of PUs assoc w/age in one study (older > younger), but not others. ${ }^{67,71,75}$ Duration: rate of PUS assoc w/duration $(<5$ years and more than 19 years duration $>$ $5-19$ years duration), ${ }^{49}$ (20>15>10 $>25>5$ years), ${ }^{11}$ (more duration $>$ less duration), (more than 20 years < less than 20 years duration). ${ }^{74}$

Course: PU prevalence stable over 16 years in one study, ${ }^{75}$ increased over time in another, ${ }^{11}$ and was stable during the first 10 years following injury, and then increased 15 years post injury in a third. ${ }^{72}$

Age: age assoc w/depression scores in some studies (aged 25-49 > older and younger), ${ }^{77}$ (younger at injury > older at injury), ${ }^{76}$ (younger $>$ older), ${ }^{51}$ but not others. ${ }^{66,80}$

Duration: duration assoc w/depression scores in one study (1-year post injury $>5$-years post injury). ${ }^{76}$

Course: depressive symptoms increased over

time in some studies, ${ }^{66,75}$ but not others. ${ }^{82}$

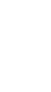


Table 1 (Continued)

\begin{tabular}{|c|c|c|c|c|c|}
\hline Condition & Articles (no.) & Publication years & $\begin{array}{c}\text { Sample size } \\
\text { (range) }\end{array}$ & Prevalence & Summary of key findings \\
\hline $\begin{array}{l}\text { Blood circulatory } \\
\text { problems including } \\
\text { hypertension, hypo- } \\
\text { tension, cardiovas- } \\
\text { cular disease (CVD), } \\
\text { thrombosis, auto- } \\
\text { nomic dysreflexia } \\
\text { (AD) }\end{array}$ & 10 & 1989-2010 & $13-545$ & $\begin{array}{l}\text { CVD: } 30-35 \%^{87} \\
\text { Coronary heart disease: } 7-24 \%^{20,87,88} \\
\text { Hypertension: } 6-25 \%^{19,20,87-89} \\
\text { Cerebrovascular disease: } 1 \%^{87} \\
\text { Dysrhythmia: } 16 \% 87 \\
\text { Valvular disease: } 7 \%^{87} \\
\text { Congestive heart failure: } 8 \%^{87} \\
\text { Hypotension last year: } 12 \%^{49} \\
\text { Thrombosis past year: } 3 \%^{49} \\
\text { AD last year (in a sample of individuals with } \\
\text { injuries at all levels): } 18 \%{ }^{37} \\
\text { History of myocardial infarction: } 6 \% 19 \\
\text { AD (in a sample of individuals with cervical } \\
\text { spinal cord injuries), time period not } \\
\text { specified: } 30 \% 36\end{array}$ & $\begin{array}{l}\text { Age: CVD assoc w/age (older } \\
\text { > younger); }{ }^{51,67,87} \text { Hypertension assoc w/age } \\
\text { (older > younger); }{ }^{51} \text { Thrombosis not assoc w/ } \\
\text { age; }{ }^{67} \text { AD assoc w/age in one study (older } \\
\text { <younger), }{ }^{51} \text { but not in another. }{ }^{67} \\
\text { Duration effects: no research identified. } \\
\text { Course: rates of CVDs increased over time post } \\
\text { injury. }^{87}\end{array}$ \\
\hline
\end{tabular}

Muscle spasms 8

1989-2008

31-781

Diabetes

Bowel problems, including constipation (constp) and fecal incontinence (FI)

Osteoporosis/low bone mineral density (BMD)

1989-2010

6

1999-2010
Current muscle spasms: $53-87 \%{ }^{39,52}$

Muscle spasms last 12 months:

$57-71 \%^{37,49,51}$

Current severe spasms: $37 \% 90$

Current mild to moderate spasms: $40 \%{ }^{90}$

70-3737

Frequency: 5-22\%6,19-21,89,92,93

$78-1668$

Current constp: $58 \% 59$

Constp last year: $32 \% 49$

Daily FI: 1-4\% ${ }^{59,94}$

Occasional FI: $49 \% 59$

$\mathrm{FI}$ in the last year: $22-31 \% 49,95$

FI 'sometimes': $32 \%{ }^{57}$

FI 'often': $5 \%{ }^{57}$

FI few times/week: $4 \%{ }^{94}$

Fl few times/month: $15 \%{ }^{94}$

FI few times/year: $56 \%{ }^{94}$

Osteoporosis: $61 \% 96$

Osteopenia: $20 \% 96$

Femur osteoporosis: $82 \%{ }^{90}$

Femur osteopenia: $13 \%{ }^{90}$

Lumbar spine osteoporosis: $17 \% 90$

Lumbar spine osteopenia: $18 \%{ }^{90}$

26-7959

Current obesity: 4-32\% ${ }^{63,93,100-102}$

Current fatigue: $19-74 \%^{37,44,57,95}$ Severe current fatigue: $36 \%{ }^{57}$
Age: spasms assoc w/age in one study (younger > older) ${ }^{51}$ but not in another. ${ }^{67}$

Duration effects: spasms not assoc w/ duration. ${ }^{49,51}$

Course: spasticity increased during inpatient rehabilitaiton, ${ }^{67}$ and may be more frequent during initial rehabilitation than in the months following discharge from initial rehabilitation. ${ }^{91}$

Age: Diabetes assoc w/age (older $>$ younger). ${ }^{92,93}$

Duration effects: no studies identified. Course: no studies identified.

Age: $\mathrm{Fl}$ assoc w/age (older $>$ younger); 66 constp not assoc w/age. ${ }^{66}$

Duration: $\mathrm{Fl}$ assoc w/duration in some studies, ${ }^{66,94}$ but not others; ${ }^{52}$ constp not assoc w/duration. 66

Course: no studies identified.

Age: age not assoc w/spine osteopenia or spine BMD loss, but is assoc w/lower hip BMD and general BMD loss. ${ }^{96,97}$

Duration: duration significantly assoc $\mathrm{w} /$ lumbar, hip, spine, knee, femur and general BMD loss. ${ }^{96-98}$

Course: leg BMD decreases more over time more in non-standing individuals (24\%) than in standing individuals; differences became significant by the second year post injury; ${ }^{38}$ BMD appears to achieve a steady state at 2 years post injury. ${ }^{99}$

Age: $\mathrm{BMI}$ assoc w/age (older > younger). ${ }^{101}$ Duration: BMI assoc w/duration (longer duration > shorter duration). ${ }^{103}$ Course: BMI increased over a 5-year period following $\mathrm{d} / \mathrm{c}$ from inpatient rehabilitation. ${ }^{101}$

Age: age assoc w/fatigue (older > younger). ${ }^{60,104}$ Duration: duration assoc w/fatigue (more duration > less duration). ${ }^{104}$

Course: no studies identified. 
Table 1 (Continued)

\begin{tabular}{|c|c|c|c|c|c|}
\hline Condition & Articles (no.) & Publication years & $\begin{array}{c}\text { Sample size } \\
\text { (range) }\end{array}$ & Prevalence & Summary of key findings \\
\hline $\begin{array}{l}\text { Respiratory pro- } \\
\text { blems, including } \\
\text { respiratory infec- } \\
\text { tions (RI) and } \\
\text { shortness of breath } \\
\text { (SoB) }\end{array}$ & 6 & 2000-2008 & $91-781$ & $\begin{array}{l}\text { RI last year: } 8-13 \% 37,49 \\
\text { Current SoB: } 34 \% 44 \\
\text { Current 'respiratory problem': } 12 \% 39 \\
\text { Respiratory problem last year: } 19 \%^{49} \\
\text { Difficulty coughing up sputum: } 13 \%^{49} \\
\text { Breathless: } 11 \% 49\end{array}$ & $\begin{array}{l}\text { Age: RIs assoc w/age (older > younger); } \\
\text { 'respiratory complications w/age. }{ }^{61} \\
\text { Duration: no studies identified. } \\
\text { Course: a slight decrease in lower RIs ove } \\
\text { course of } 5 \text { years, but no change in rate } \\
\text { upper RIs over } 5 \text { years. }{ }^{105}\end{array}$ \\
\hline Bone fractures/falls & 5 & 2001-2005 & $41-1092$ & $\begin{array}{l}\text { Fractures: } 21-34 \%{ }^{22,96,106} \\
\text { Fractures per year: } 2 \%^{22} \\
\text { Falls in the past year: } 21-31 \%^{37,107} \\
\text { Injured due to falls past year: } 14 \% 107 \\
\text { Death due to falls past year:. } 002 \% \text { ( } 1 \text { out of } \\
659)^{107}\end{array}$ & $\begin{array}{l}\text { Age: no studies identified. } \\
\text { Duration: falls assoc w/duration (shorter } \\
\text { > longer duration). }{ }^{107} \\
\text { Course: no studies identified. }\end{array}$ \\
\hline $\begin{array}{l}\text { Problems with sex- } \\
\text { ual activity }\end{array}$ & 4 & 1989-2007 & $78-454$ & $\begin{array}{l}\text { Sex problems in the last year: } 39 \% 49 \\
\text { Decreased sexual functioning since injury: } \\
73 \% 52 \\
\text { Current complications with sexual activity: } \\
45 \% 108 \\
\text { Women reporting lack of adequate } \\
\text { lubrication during sexual stimulation: } \\
28 \% 109 \\
\text { Women reporting lack of genital sensation: } \\
41 \% 109\end{array}$ & $\begin{array}{l}\text { Age: no studied identified. } \\
\text { Duration: no studies identified. } \\
\text { Course: no studies identified. }\end{array}$ \\
\hline
\end{tabular}

Heterotopic ossifi- $4 \quad 1998-2008 \quad 204-782$ Rate of HO: 6-18\% ${ }^{49,51,110}$

\author{
'Sleep problems' \\ including obstruc- \\ tive sleep apnea \\ (OSA)
}

Contractures

3

2000-2005

Excessive sweating 2

2002-2005

454-1668

Esophageal symptoms, including dysphagia Dental problems
1

1993

2009
93
91-1668

33-747

Rate of OSA: $15 \%^{111}$ Rate of
$53 \%{ }^{112}$

Rate of contractures in the last 12 month: 9-23\% 37,49

Rate of contractures occurring 'sometimes' (53\%) or 'often' (32\%): $85 \%{ }^{57}$
Age: rate of $\mathrm{HO}$ assoc w/age in some studies (younger > older), ${ }^{51,110}$ but not others. ${ }^{67}$ Duration: rate of $\mathrm{HO}$ assoc w/duration in some studies (more duration > less duration), ${ }^{51}$ but not others. 49

Course: no studies identified.

Age: rate of OSA assoc w/age (older

: younger) $^{23}$

Duration: no studies identified.

Course: no studies identified.

Age: no studies identified.

Duration: rate of contractures assoc w/duration

(older than 19 years $>$ younger than 19

years). 49

Course: no studies identified.

Rate of 'excessive sweating' in the past 12 Age: no studies identified. months: $28 \% 49$

Rate of 'excessive sweating' 'sometimes' (36\%) or 'often' (11\%): $47 \%{ }^{57}$

Rate of heart burn: $61 \% 113$

Rate of esophageal chest pain: $33 \%{ }^{113}$

Rate of intermittent dysphagia: $30 \%{ }^{113}$

Current oral problems needing treatment: $47 \% 114$

Oral pain past 12 months: $47 \% 114$
Duration: no studies identified.

Course: no studies identified.

Age: no studies identified. Duration: no studies identified. Course: no studies identified. Age: no studies identified. Duration: no studies identified. Course: no studies identified.

aSample size refers to sample of participants in the study with SCl.

found for falls and depression. For sexual activity, excessive sweating, esophageal symptoms and dental problems, we were not able to identify any study that examined its association with age or duration.

\section{Time course of secondary health conditions}

The time course of conditions was only rarely studied using longitudinal research designs (Table 1). Pain is the condition most often studied with respect to course. The findings indicate that once chronic pain develops in persons with SCI, it tends to remain stable. Arm/shoulder and leg pain are notable exceptions; arm pain tends to worsen over time and leg pain may decrease over time.

There are fewer findings regarding the course of the other conditions. The course of pressure ulcers has been studied, but the findings are inconsistent. Two studies indicate that the prevalence of 
Table 2 Relative importance ratings or rankings of different secondary health conditions in individuals with spinal cord injury

\begin{tabular}{ll}
\hline Author(s) & Sample description \\
\hline Bloeman-Vrencken & Four hundred fifty-four respondents to a survey \\
et al.49 & $\begin{array}{l}\text { sent to 'members of the Dutch Association of } \\
\text { Spinal Cord Injured patients' }\end{array}$
\end{tabular}
Spinal Cord Injured patients'

Klotz et al. ${ }^{57}$ One thousand six hundred sixty-eight respondents to a survey sent to individuals with tetraplegia
Comparison method

Relative frequency and relative \% of respondents who mentioned a problem (of 13 'secondary impairments in individuals with $\mathrm{SCl}$ might experience') in top 5 most important
Key findings

The relative frequency of the 'secondary impairments' and \% of respondents who mentioned the problem in the top 5 of importance were, in order, bladder regulation problems (71 and $52 \%$ ), bowel regulation problems (61 and $42 \%$ ), spasms (57 and 33\%), pain (55 and $40 \%$ ), edema in legs (49 and $16 \%$ ), problems with pressure sores (36 and $21 \%$ ), increasing weight (32 and 14\%), excessive sweating (28 and $9 \%$ ), contractures (23 and 7\%), breathing/ respiratory tract problems (19 and $7 \%$ ), heterotopic ossification (13 and 4\%), low blood pressure (12 and $2 \%$ ) and thrombosis (3 and 1\%).

Relative frequency that a condition was listed as The rates of reasons for rehospitalizations were, a 'reason for rehospitalization' following the initial hospitalization

in order, urinary complications (32\%), systematic follow-up (28\%), pressure sores (20\%), respiratory complications (14\%), contractures (14\%) bowel complications (10\%), pain (9\%) and secondary fractures $(8 \%)$.

Relative frequency of 18 'health complications' The relative rates of the 18 'health complications' were, in order, spasticity $(71 \%)$, shoulder pain $(59 \%)$, chronic pain $(58 \%)$, bladder infections (57\%), arthritis/joint pain (53\%), bowel problems (43\%) depression (35\%), distress $(33 \%)$, pressure ulcers $(29 \%)$, high blood pressure (23\%), autonomic dysreflexia (20\%), respiratory complications (16\%), bladder/kidney problems (13\%), neurological deterioration $(13 \%)$, heterotopic ossification $(6 \%)$, fractures (7\%), cardiac complication (7\%) and drug addiction (4\%).

Krause ${ }^{115} \quad$ Four hundred forty nine participants in a longitudinal survey

Relative importance ratings ( $1=$ no problem; $5=$ major problem) of 'problems... typically experienced by people with SCl'

The relative importance of specific healthrelated problems were, in order, pain (2.76), spasms (2.37), sex life (2.20), emotional pain (1.78), sweats and chills (1.73), depression (1.67), skin sores (1.65) and sadness (1.64).

Relative frequency of experiencing ' 17 specific secondary conditions' in the previous 12 months
The relative frequency of each condition in the last 12 months was, in order, spasms (70\%), shoulder pain or other repetitive stress injury $(52 \%)$, fatigue $(51 \%)$, urinary tract infections (48\%), chronic pain (45\%), skin problems (33\%), anxiety (24\%), depression (22\%), falls or other injuries (21\%), autonomic dysreflexia (18\%), respiratory infections (13\%), reactions to medications ( $12 \%$ ), contractures $(9 \%)$, burns $(9 \%)$, asthma (3\%) and osteoporosis $(2 \%)$.

Abbreviation: $\mathrm{SCl}$, spinal cord injury.

pressure ulcers is stable over time-in one study, for as long as 16 years-while another study indicated stability in the prevalence of pressure ulcers only in the first 10 years following injury, followed by an increase in prevalence. Findings regarding the course of depression are likewise inconsistent, with the results suggesting either stability or a gradual increase in depressive symptoms over time. Note that this finding of a gradual increase in depression symptoms (in one study only) over time is inconsistent with the findings of a negative association between depression and age in non-SCI samples.

The prevalence of cardiovascular disease was shown to increase over time in one longitudinal study. This longitudinal finding is consistent with the significant positive concurrent associations found between both age and SCI duration and cardiovascular disease. Also, BMI was shown to increase over a 5-year period in one longitudinal study, consistent with the significant positive associations between both age and duration and BMI in concurrent correlation analyses.

\section{Comparison of prevalence or severity of conditions relative to normative samples}

Of the 20 health conditions examined in this review, only eight (40\%) were compared with normative values or to a normative sample (of 
individuals without SCI). ${ }^{6,14-23}$ In all but one case, health conditions were found to be more frequent or severe in the SCI sample than in the normative group. These included pain, depression, cystitis (as a bladder problem), cardiovascular disease, diabetes, fractures, sleep problems and esophageal problems. Only prevalence of bladder cancer was not more frequent in the SCI sample relative to the normative sample. ${ }^{17,18}$ In no case was a health condition found to be less prevalent in the SCI sample.

\section{DISCUSSION}

The key findings from this study are that (1) individuals with SCI experience a large number of serious secondary health conditions, many of which occur at a significantly higher rate in persons with SCI than the normative population; (2) the most common conditions are pain, bowel and bladder regulation problems, muscle spasms, fatigue, heart burn and osteoporosis; (3) a number of these conditionsincluding cardiovascular disease, diabetes, BMD loss, fatigue and respiratory complications/infections-occur with higher frequency in older individuals or those with greater SCI duration, relative to younger individuals or those with shorter SCI duration; and (4) there is a lack of longitudinal research examining the natural course of secondary health conditions in individuals with SCI, and the findings from the limited studies are often inconsistent, with only cardiovascular disease and weight (as measured by BMI) showing increases over time. These findings have important clinical and research implications.

\section{Conditions that are most common and important to patients}

In terms of overall frequency and rated importance to patients, three health conditions stood out: pain, bladder problems and bowel problems. Both neuropathic (pain caused by a lesion or disease of the somatosensory system) and nociceptive pain types are common, and the most frequent pain sites are back and shoulder/arm. Pain is also a reason for rehospitalization. Individuals with SCI listed it as the single more important secondary conditions in one study, and pain was listed as among the 'top 5' important conditions by patients in another study (just after bladder and bowel regulation problems).

This finding regarding pain underscores what many clinicians know from their daily practice: pain is a very serious problem in many individuals with SCI that is highly refractory to treatments that are currently available. ${ }^{24}$ The finding supports the need to continue to identify effective pain treatments and pain prevention strategies for SCI-related pain.

In particular, 'arm pain' that tends to worsen over time may reflect shoulder and arm pain resulting from manual wheelchair use, and perhaps also incorrect transfer approaches. This finding supports the need for studies that will examine the association between and impact of over-use and specific transfer skills on fall frequency. Such research could then inform the development of interventions that would address accommodations needed to ensure safe transfers as people age or as changes occur in their weight. The transfer techniques that a patient uses at age 25 may not be suitable for the same patient at age 60 .

Bowel and bladder problems were also identified as among the most common and important to patients in this review. The severity of these problems can be contrasted to the lack of research to develop and evaluate the efficacy of treatments to improve these problems. For example, a PubMed search using the keywords 'bowel' or 'bladder' and 'SCI' in the title, and limiting the search to clinical trials (performed on 7 March 2013) yielded very few studies (28), only 21 of which were actually pilot or clinical trials examining the efficacy of different approaches to bowel or bladder problems. However, some silver lining can be found by an increase in this research, given that almost as many clinical trials (7) were published in the 4 years from 2009-2012 as were published in the 8 years before this $(8$ clinical trials; from 2001-2008). This trend for an increasing number of research studies on bowel and bladder problems should be supported.

Other common conditions or symptoms identified in this review include muscle spasms, fatigue, heart burn, osteoporosis/bone density loss, pressure ulcers, obesity, excessive sweating, depression, cardiovascular disease including high blood pressure, bone fractures/falls, problems with sexual activity, esophageal chest pain, intermittent dysphagia and dental/oral problems. Although some of these conditions (for example, pressure ulcers) often get significant attention by clinicians who are familiar with SCI, others (for example, dental problems) may receive less attention. Clinicians should therefore be particularly vigilant in monitoring for these conditions, and treat as indicated, in order to maximize the health and well-being of the individuals with SCI they serve.

In our view, the loss of bone density seen with age is a particularly serious problem that deserves additional research and clinical attention. Although research has yet to examine an association between low BMD and higher risk for fractures in individuals with SCI, osteoporosis is a known risk factor for fractures in the general population. ${ }^{25}$ Everything possible should be done for bone health. Moreover, in our view, regular therapy check-ups to observe and teach transfer methods that match the age and abilities of the individual would be useful.

\section{Findings regarding age and duration effects}

The findings regarding the associations between chronological age/ SCI duration and the prevalence of the secondary health conditions studied are somewhat complicated to interpret given both the statistical confounding between age and SCI duration and the potential selection bias effects of survey results. For example, it is possible that any significant association found between age or duration and a condition could potentially be due to the effects of either age or duration (or even both), given that the predictor variables are associated with one another. Determination of the unique effects of either on a health condition requires that the other be controlled in the analyses; ideally age at SCI onset should also be controlled in such analyses. This can be performed via a series of three regression analyses, with a measure of the health condition as the criterion variable, one of three age variables (chronological age, age at SCI onset and time since injury onset) as the primary predictor, and one of the other age variables as a control variable. ${ }^{13}$ The analyses must be performed as a series of three analyses with two of the age predictor variables entered in any one equation, because of the multicollinearity problems that would occur if all three were entered in the same equation. However, the majority of studies that tested for significant associations failed to control for these confounding factors. The second issue - potential selection bias-is related to the possibility that different age groups of responders in survey studies may not be representative of the same population (for example, see studies by Christensen et $a .^{26}$ ). For example, responders to surveys of populations who do not have SCI have been shown to be healthier than non-responders. ${ }^{27,28}$ If this finding were to extend to populations with SCI, then the older cohorts of survey responders might be expected to be among the 'healthier' individuals, relative to younger responders. This would result in an under-estimate of the association between age or duration and the frequency or severity of health conditions. This may explain, at least in part, some of the 
inconsistent findings in the studies reviewed here, with age or duration sometimes being shown to be associated with a health condition and sometimes not.

Despite these limitations and caveats, however, a number of age and SCI duration effects were found which allows for preliminary conclusions. Those conditions with the most consistent positive associations with age and/or duration include cardiovascular disease, diabetes, BMD loss, fatigue and respiratory complications. Those conditions with less but still some support (that is, effects found in one study only or significant in some studies but not others) for being more frequent or severe in older individuals or those with longer duration, include fecal incontinence, obstructive sleep apnea and contractures. Depression and falls showed inconsistent associations with SCI duration, but when significant effects were found, they were negatively associated with age or duration (more severe or common in younger as opposed to older individuals). Only two conditions demonstrated a consistent lack of significant association with age or duration: bladder problems and spasms.

As a group, the findings provide preliminary support for the conclusion that older age and longer SCI duration tend to be associated with more frequent and severe health conditions. This conclusion, given the concomitant finding that many secondary conditions are more frequent in individuals with SCI relative to those without a SCI, are consistent with the 'premature aging' hypothesis. ${ }^{2,5-7}$

\section{Implications for research, policy and practice}

Research. In addition to the need to continue to develop and evaluate the efficacy of prevention programs and treatments for secondary health conditions in individuals with SCI, there is a need for longitudinal studies to more accurately evaluate the natural course of health conditions in individuals with SCI. This scoping study identified a list of conditions that are common in individuals with SCI. The challenge now is to track those conditions and determine when they are likely to emerge and how they impact function, in order to know when to provide treatments that could help prevent them. Unfortunately, only $22(24 \%)$ of the 92 studies included in this review utilized a longitudinal design. Such designs are urgently needed for the field to better understand the natural course and effects of secondary conditions on the quality of life in individuals with SCI. This knowledge would help us better anticipate when the needs of individuals with SCI are most likely to arise.

As noted in this review, there were some inconsistencies in the findings, and the reasons for these inconsistencies are not entirely clear. It is possible that they reflect the true nature of the relationships between age, duration, and secondary health conditions-that the associations may be stronger or weaker in different samples of individuals, and are therefore moderated by some as-yet unidentified variable or variables. In addition, the studies reviewed used a large variety of designs and measures. Differences in these factors may explain some of the inconsistencies across studies. We anticipate that such inconsistencies may become less over time as researchers develop and begin to use measures developed specifically for individuals with SCI. For example, the International Spinal Cord Society has identified specific measures for assessing a large variety of conditions, such as urinary track function, ${ }^{29}$ bowel function, ${ }^{30}$ cardiovascular function ${ }^{31}$ and pain, ${ }^{32}$ among others. However, given the real possibility that different investigators may continue to use different measures, the field would benefit from more 'cross walking' of measures to allow for comparisons. ${ }^{33}$
Policy. At least two clear policy implications emerge from the findings from this scoping review. First, the findings point to the need to include questions about disability status in the large ongoing national health data collection studies such as the National Health Interview Survey and the Behavioral Risk Factor Surveillance System. The inclusion of just one question regarding the presence of a specific diagnosis associated with disability, especially if the list of possible diagnoses represented a variety of types (for example, multiple sclerosis, SCI and muscular dystrophy) would allow us to answer many critical questions regarding the frequency, impact and course of health conditions in individuals aging with disabilities without the need for any additional longitudinal surveys. Second, the findings demonstrate a significant health need in an important part of the population, and therefore a critical need for additional funding for both research (to better understand the factors contributing to the prevalence and impact of secondary conditions in individual aging with disabilities) as well as for providing preventative services and treatment to minimize their prevalence and negative impact.

Practice. The findings from this scoping review provide strong support for the need for greater efforts to prevent and buffer the negative impacts of these conditions. Many of the most common conditions identified, such as cardiovascular disease, diabetes, BMD loss, fatigue, obstructive sleep apnea appear to be related to a sedentary lifestyle, obesity or both. Significant effort may be needed to develop and evaluate the efficacy of ways for individuals with SCI to (1) increase weight-bearing and both improve and maintain cardiovascular fitness ${ }^{34}$ and (2) help individuals with SCI avoid gaining weight as they age. Treatments that successfully address these factors may prevent or ameliorate a large number of the secondary conditions that in our review were associated with increasing age.

\section{Limitations of the review}

The current review has a number of limitations that should be considered when interpreting the results. First, given the limitations associated with a scoping review, there are very likely studies that provide information about the frequency or course of secondary health conditions in individuals with SCI that were not identified or included in this review. However, the search strategy used likely identified the majority of the key studies, and thus the findings probably accurately reflect the types and overall prevalence of the conditions discussed. In addition, two factors related to age-age at injury and year of injury (era or birth cohort effects) - were not examined in this review. Both of these likely have an important role for at least some of the health conditions. ${ }^{10,35}$ Another important issue likely related to the prevalence, severity and impact of secondary conditions is the level and severity of the lesion. Support for this conclusion can be seen in the findings of this review. For example, autonomic dysreflexia was more frequent in a sample of individuals with cervical injury ${ }^{36}$ than in a sample of made of individuals with injuries at all levels. ${ }^{37}$ Similarly, one of the studies reviewed reported that leg BMD decreases more rapidly over time in non-standing individuals than in standing individuals. ${ }^{38}$ However, examination of the associations between lesion severity and secondary conditions was not one of the foci of this review, and data were not extracted specifically to address this question. A systematic review that examines these addition specific factors is warranted. Relatedly, like all literature reviews of this nature, we were limited by the search engines and search terms, with regards to what evidence we identified, and our analysis is limited by the articles identified. Systematic 
reviews focusing on one or more of the following specific topics would be helpful to obtain determine (1) the frequency and course of secondary conditions in the first year following injury, (2) the associations between age at injury and year of injury and the prevelance and course of secondary conditions, and (3) the specific frequency, course and association with age of some of the more common secondary conditions, such as pain, pressure ulcers, depression and urinary tract infections.

\section{Summary and conclusions}

The current scoping review provides important summary information regarding the frequency and course of secondary health conditions in individuals with SCI. The most common secondary conditions and symptoms that were identified are pain, bowel and bladder regulation problems, muscle spasms, fatigue, heart burn and osteoporosis. Many of these and the other secondary conditions identified occur at a higher rate in older than in younger individuals with SCI, and occur with a greater frequency in individuals with SCI than in individuals who do not have a SCI. However, there is a marked lack of longitudinal studies that provide evidence regarding the natural course of these conditions and their impact on quality of life. The findings underscore the need for such studies, as well as studies that develop and test interventions that would prevent the onset of these health conditions, lower their severity and minimize their impact.

\section{DATA ARCHIVING}

There were no data to deposit.

\section{CONFLICT OF INTEREST}

The authors declare no conflict of interest.

\section{ACKNOWLEDGEMENTS}

This study was supported by a research grant from the Department of Education (National Institute on Disability and Rehabilitation Research [NIDRR] Grant no. H133B080024). The article contents do not necessarily represent the policy of the Department of Education, and readers should not assume endorsement by the Federal Government. The authors express their appreciation to Anna Harrington and Macklin Nguyen, who helped with the data extraction process.

1 Jensen MP, Molton IR, Groah SL, Cmapbell ML, Charilifue S, Chiodo A et al Secondary health conditions in individuals aging with $\mathrm{SCl}$ : terminology, concepts and analytic approaches. Spinal Cord 2012; 50: 373-378.

2 Hitzig SL, Eng JJ, Miller WC, Sakakibara BM. An evidence-based review of aging of the body systems following spinal cord injury. Spinal Cord 2011; 49: 684-701.

3 Rimmer JH, Chen MD, Hsieh K. A conceptual model for identifying, preventing, and managing secondary conditions in people with disabilities. Phys Ther 2011; 91 1728-1739.

4 Institute of Medicine. Prevention of Secondary Conditions. In: Pope AM and Tarlov AR eds. Disability in America: Toward a National Agenda for Prevention. The National Academies Press, 1991.

5 Kemp B, Thompson L. Aging and spinal cord injury: medical, functional, and psychosocial changes. SCI Nurs 2002; 19: 51-60.

6 Bauman WA, Spungen AM. Disorders of carbohydrate and lipid metabolism in veterans with paraplegia or quadriplegia: a model of premature aging. Metabolism 1994; 43: 749-756.

7 Ohry A, Shemesh Y, Rozin R. Are chronic spinal cord injured patients (SCIP) prone to premature aging? Med Hypotheses 1983; 11: 467-469.

8 Capoor J, Stein AB. Aging with spinal cord injury. Phys Med Rehabil Clin N Am 2005; 16: 129-161.

9 Thompson L. Functional changes in persons aging with spinal cord injury. Assist Technol 1999; 11: 123-129.

10 Adkins $\mathrm{RH}$. Research and interpretation perspectives on aging related physical morbidity with spinal cord injury and brief review of systems. NeuroRehabilitation 2004; 19: 3-13.
11 Charlifue S, Lammertse DP, Adkins RH. Aging with spinal cord injury: changes in selected health indices and life satisfaction. Arch Phys Med Rehabil 2004; 85 1848-1853.

12 Arksey H, O'Malley L. Scoping studies: Towards a methodological framework. Int J Soc Res Methodol 2005; 8: 19-32.

13 Hirsh AT, Molton IR, Johnson KL, Bombardier $\mathrm{CH}$, Jensen MP. The relationship of chronological age, age at injury, and duration of injury to employment status in individuals with spinal cord injury. Psychol Inj Law 2009; 2: 263-275.

14 Jensen MP, Hoffman AJ, Cardenas DD. Chronic pain in individuals with spinal cord injury: a survey and longitudinal study. Spinal Cord 2005; 43: 704-712.

15 Oh SJ, Shin HI, Paik NJ, Yoo T, Ku JH. Depressive symptoms of patients using clean intermittent catheterization for neurogenic bladder secondary to spinal cord injury. Spinal Cord 2006; 44: 757-762.

16 Imai K, Kadowaki T, Aizawa Y, Fukutomi K. Problems in the health management of persons with spinal cord injury. J Clin Epidemiol 1996; 49: 505-510.

17 Pannek J. Transitional cell carcinoma in patients with spinal cord injury: a high risk malignancy? Urology 2002; 59: 240-244.

18 Subramonian K, Cartwright RA, Harnden P, Harrison SC. Bladder cancer in patients with spinal cord injuries. BJU Int 2004; 93: 739-743.

19 Wahman K, Nash MS, Westgren N, Lewis JE, Seiger A, Levi R. Cardiovascular disease risk factors in persons with paraplegia: The Stockholm spinal cord injury study. J Rehabil Med 2010; 42: 272-278.

20 Yekutiel M, Brooks ME, Ohry A, Yarom J, Carel R. The prevalence of hypertension, ischaemic heart disease and diabetes in traumatic spinal cord injured patients and amputees. Paraplegia 1989; 27: 58-62.

21 Lavela SL, Weaver FM, Goldstein B, Chen K, Miskevics S, Rajan S et al. Diabetes mellitus in individuals with spinal cord injury or disorder. J Spinal Cord Med 2006, 29: 387-395.

22 Vestergaard P, Krogh K, Rejnmark L, Mosekilde L. Fracture rates and risk factors for fractures in patients with spinal cord injury. Spinal Cord 1998; 36: 790-796.

23 Biering-Sorensen F, Biering-Sorensen M. Sleep disturbances in the spinal cord injured: an epidemiological questionnaire investigation, including a normal population. Spinal Cord 2001; 39: 505-513.

24 Ragnarsson KT. Management of pain in persons with spinal cord injury. J Spinal Cord Med 1997; 20: 186-199.

25 Dempster DW. Osteoporosis and the burden of osteoporosis-related fractures. Am J Manag Care 2011; 17 (Suppl), S164-S169.

26 Christensen Al, Ekholm O, Glumer C, Andreasen AH, Hvidberg MF, Kristensen PL et al. The Danish National Health Survey 2010. Study design and respondent characteristics. Scand J Public Health 2012; 40: 391-397.

27 O'Neill TW, Marsden D, Silman AJ. Differences in the characteristics of responders and non-responders in a prevalence survey of vertebral osteoporosis. European Vertebral Osteoporosis Study Group. Osteoporos Int 1995; 5: 327-334.

28 Volken T. Second-stage non-response in the Swiss health survey: determinants and bias in outcomes. BMC Public Health 2013; 13: 167.

29 Biering-Sorensen F, Craggs M, Kennelly M, Schick E, Wyndaele JJ. International lower urinary tract function basic spinal cord injury data set. Spinal Cord 2008; 46 325-330.

30 Krogh K, Perkash I, Stiens SA, Biering-Sorensen F. International bowel function basic spinal cord injury data set. Spinal Cord 2009; 47: 230-234.

31 Krassioukov A, Alexander MS, Karlsson AK, Donovan W, Mathias CJ, Biering Sorensen F. International spinal cord injury cardiovascular function basic data set. Spinal Cord 2010; 48: 586-590.

32 Biering-Sorensen F, Charlifue S, Devivo MJ, Grinnon ST, Kleitman N, Lu Y et al. Incorporation of the International Spinal Cord Injury Data Set elements into the National Institute of Neurological Disorders and Stroke Common Data Elements. Spinal Cord 2011; 49: 60-64.

33 Noonan VK, Cook KF, Bamer AM, Choi SW, Kim J, Amtmann D. Measuring fatigue in persons with multiple sclerosis: creating a crosswalk between the Modified Fatigue Impact Scale and the PROMIS Fatigue Short Form. Qual Life Res 2012; 21: 1123-1133.

34 Alexeeva N, Sames C, Jacobs PL, Hobday L, Distasio MM, Mitchell SA et al. Comparison of training methods to improve walking in persons with chronic spinal cord injury: a randomized clinical trial. J Spinal Cord Med 2011; 34: 362-379.

35 Thompson L, Yakura J. Aging related functional changes in persons with spinal cord injury. Top Spinal Cord Inj Rehabil 2001; 6: 69-82.

36 Widerstrom-Noga E, Cruz-Almeida Y, Krassioukov A. Is there a relationship between chronic pain and autonomic dysreflexia in persons with cervical spinal cord injury? J Neurotrauma 2004; 21: 195-204.

37 Prysak GM, Andresen EM, Meyers AR. Prevalence of secondary conditions in veterans with spinal cord injury and their interference with life activities. Topics in Spinal Cord Injury Rehabilitation 2000; 6: 34-42.

38 Alekna V, Tamulaitiene M, Sinevicius T, Juocevicius A. Effect of weight-bearing activities on bone mineral density in spinal cord injured patients during the period of the first two years. Spinal Cord 2008; 46: 727-732.

39 Walter JS, Sacks J, Othman R, Tankin AZ, Nemchausky B, Chintam R et al. A database of self-reported secondary medical problems among VA spinal cord injury patients: its role in clinical care and management. J Rehabil Res Dev 2002; 39 53-61.

40 Siddall PJ, McClelland JM, Rutkowski SB, Cousins MJ. A longitudinal study of the prevalence and characteristics of pain in the first 5 years following spinal cord injury. Pain 2003; 103: 249-257. 
41 Young ME, Rintala DH, Rossi CD, Hart KA, Fuhrer MJ. Alcohol and marijuana use in a community-based sample of persons with spinal cord injury. Arch Phys Med Rehabil 1995; 76: 525-532.

42 Roth E, Davidoff G, Thomas P, Doljanac R, Dijkers M, Berent S et al. A controlled study of neuropsychological deficits in acute spinal cord injury patients. Paraplegia 1989; 27: 480-489.

43 Ravenscroft A, Ahmed YS, Burnside IG. Chronic pain after SCI. A patient survey. Spinal Cord 2000; 38: 611-614.

44 Jensen MP, Kuehn CM, Amtmann D, Cardenas DD. Symptom burden in persons with spinal cord injury. Arch Phys Med Rehabil 2007; 88: 638-645.

45 Rintala DH, Loubser PG, Castro J, Hart KA, Fuhrer MJ. Chronic pain in a communitybased sample of men with spinal cord injury: prevalence, severity, and relationship with impairment, disability, handicap, and subjective well-being. Arch Phys Med Rehabil 1998; 79: 604-614.

46 Turner JA, Cardenas DD, Warms CA, McClellan CB. Chronic pain associated with spinal cord injuries: a community survey. Arch Phys Med Rehabil 2001; 82: 501-509.

47 Stormer S, Gerner HJ, Gruninger W, Wetzmacher K, Follinger S, Wienke C et al. Chronic pain/dysaesthesiae in spinal cord injury patients: results of a multicentre study. Spinal Cord 1997; 35: 446-455.

48 Cardenas DD, Bryce TN, Shem K, Richards JS, Elhefni H. Gender and minority differences in the pain experience of people with spinal cord injury. Arch Phys Med Rehabil 2004; 85: 1774-1781.

49 Bloemen-Vrencken JHA, Post MWM, Hendriks JMS, de Reus ECE, de Witte LP. Health problems of persons with spinal cord injury living in the Netherlands. Disabil Rehabil 2005; 27: 1381-1389.

50 Budh CN, Osteraker AL. Life satisfaction in individuals with a spinal cord injury and pain. Clin Rehabil 2007; 21: 89-96.

51 Hitzig SL, Tonack M, Campbell KA, McGillivray CF, Boschen KA, Richards K et al. Secondary health complications in an aging Canadian spinal cord injury sample. Am J Phys Med Rehabil 2008; 87: 545-555

52 Widerstrom-Noga EG, Felipe-Cuervo E, Broton JG, Duncan RC, Yezierski RP. Perceived difficulty in dealing with consequences of spinal cord injury. Arch Phys Med Rehabil 1999; 80: 580-586.

53 Vall J, Costa CM, Santos Tde J, Costa SB. Neuropathic pain characteristics in patients from Curitiba (Brazil) with spinal cord injury. Arq Neuropsiquiatr 2011; 69: 64-68.

54 Finnerup NB, Faaborg P, Krogh K, Jensen TS. Abdominal pain in long-term spinal cord injury. Spinal Cord 2008; 46: 198-203.

55 Barrett H, McClelland JM, Rutkowski SB, Siddall PJ. Pain characteristics in patients admitted to hospital with complications after spinal cord injury. Arch Phys Med Rehabil Jun 2003; 84: 789-795.

56 Gironda RJ, Clark ME, Neugaard B, Nelson A. Upper limb pain in a national sample of veterans with paraplegia. J Spinal Cord Med 2004; 27: 120-127.

57 Klotz R, Joseph PA, Ravaud JF, Wiart L, Barat M. The Tetrafigap Survey on the longterm outcome of tetraplegic spinal cord injured persons: Part III. Medical complications and associated factors. Spinal Cord 2002; 40: 457-467.

58 Stone JM, Nino-Murcia M, Wolfe VA, Perkash I. Chronic gastrointestinal problems in spinal cord injury patients: a prospective analysis. Am J Gastroenterol 1990; 85: 1114-1119.

59 De Looze D, Van Laere M, De Muynck M, Beke R, Elewaut A. Constipation and other chronic gastrointestinal problems in spinal cord injury patients. Spinal Cord 1998, 36: 63-66.

60 McColl MA, Charlifue S, Glass C, Lawson N, G Savic. Aging, Gender, and spinal cord injury. Arch Phys Med Rehabil 2004; 85: 363-367.

61 Samuelsson KA, Tropp H, Gerdle B. Shoulder pain and its consequences in paraplegic spinal cord-injured, wheelchair users. Spinal Cord 2004; 42: 41-46.

62 Alm M, Saraste H, Norrbrink C. Shoulder pain in persons with thoracic spinal cord injury: prevalence and characteristics. J Rehabil Med 2008; 40: 277-283.

63 McCasland LD, Budiman-Mak E, Weaver FM, Adams E, Miskevics S. Shoulder pain in the traumatically injured spinal cord patient: evaluation of risk factors and function. J Clin Rheumatol 2006; 12: 179-186.

64 Curtis KA, Drysdale GA, Lanza RD, Kolber M, Vitolo RS, West R. Shoulder pain in wheelchair users with tetraplegia and paraplegia. Arch Phys Med Rehabil 1999; 80: 453-457.

65 Sie IH, Waters RL, Adkins RH, Gellman H. Upper extremity pain in the postrehabilitation spinal cord injured patient. Arch Phys Med Rehabil 1992; 73: 44-48.

66 Weitzenkamp DA, Jones RH, Whiteneck GG, Young DA. Ageing with spinal cord injury: cross-sectional and longitudinal effects. Spinal Cord 2001; 39: 301-309.

67 Haisma JA, van der Woude LH, Stam HJ, Bergen MP, Sluis TA, Post MW et al. Complications following spinal cord injury: occurrence and risk factors in a longitudinal study during and after inpatient rehabilitation. J Rehabil Med 2007; 39 393-398.

68 Subbarao JV, Klopfstein J, Turpin R. Prevalence and impact of wrist and shoulder pain in patients with spinal cord injury. J Spinal Cord Med 1995; 18: 9-13.

69 Fuhrer MJ, Garber SL, Rintala DH, Clearman R, Hart KA. Pressure ulcers in community-resident persons with spinal cord injury: prevalence and risk factors. Arch Phys Med Rehabil 1993; 74: 1172-1177.

70 Saladin LK, Krause JS. Pressure ulcer prevalence and barriers to treatment after spinal cord injury: Comparisons of four groups based on race-ethnicity. NeuroReh abilitation 2009; 24: 57-66.

71 Ash D. An exploration of the occurrence of pressure ulcers in a British spinal injuries unit. J Clin Nurs 2002; 11: 470-478.
72 Chen Y, Devivo MJ, Jackson AB. Pressure ulcer prevalence in people with spinal cord injury: age-period-duration effects. Arch Phys Med Rehabil 2005; 86: 1208-1213.

73 Perkash A, Brown M. Anemia in patients with traumatic spinal cord injury. J Am Paraplegia Soc 1986; 9: 10-15.

74 Smith BM, Guihan M, LaVela SL, Garber SL. Factors predicting pressure ulcers in veterans with spinal cord injuries. Am J Phys Med Rehabil 2008; 87: 750-757.

75 Savic G, Charlifue S, Glass C, Soni BM, Gerhart KA, Jamous MA. British Ageing with $\mathrm{SCl}$ Study: changes in physical and psychosocial outcomes over time. Topics Spinal Cord Injury Rehabil 2010; 15: 41-53.

76 Arango-Lasprilla JC, Ketchum JM, Starkweather A, Nicholls E, Wilk AR. Factors predicting depression among persons with spinal cord injury 1 to 5 years post injury. NeuroRehabilitation 2011; 29: 9-21.

77 Bombardier CH, Richards JS, Krause JS, Tulsky D, Tate DG. Symptoms of major depression in people with spinal cord injury: implications for screening. Arch Phys Med Rehabil 2004; 85: 1749-1756.

78 Hughes RB, Swedlund N, Petersen N, Nosek MA. Depression and women with spinal cord injury. Topics Spinal Cord Injury Rehabil 2001; 7: 16-24.

79 Kalpakjian CZ, Albright KJ. An examination of depression through the lens of spinal cord injury: comparative prevalence rates and severity in women and men. Women Health Issues 2006; 16: 380-388.

80 Scivoletto G, Petrelli A, Di Lucente L, Castellano V. Psychological investigation of spinal cord injury patients. Spinal Cord 1997; 35: 516-520.

81 Fann JR, Bombardier CH, Richards JS, Tate DG, Wilson CS, Temkin N. Depression after spinal cord injury: comorbidities, mental health service use, and adequacy of treatment. Arch Phys Med Rehabil 2011; 92: 352-360.

82 Pollard C, Kennedy P. A longitudinal analysis of emotional impact, coping strategies and post-traumatic psychological growth following spinal cord injury: A 10-year review. Br J Health Psychol 2007; 12: 347-362.

83 Judd FK, Brown DJ. Psychiatric consultation in a spinal injuries unit. Aust NZ J Psychiatry 1992; 26: 218-222.

84 Smith BM, Weaver FM, Ullrich PM. Prevalence of depression diagnoses and use of antidepressant medications by veterans with spinal cord injury. Am J Phys Med Rehabil 2007; 86: 662-671.

85 Bejany DE, Lockhart JL, Rhamy RK. Malignant vesical tumors following spinal cord injury. J Urol 1987; 138: 1390-1392.

86 Shin JC, Park Cl, Kim SH, Yang EJ, Kim EJ, Rha DW. Abdominal ultrasonography findings in patients with spinal cord injury in Korea. J Korean Med Sci 2006; 21: 927-931.

87 Groah SL, Weitzenkamp D, Sett P, Soni B, Savic G. The relationship between neurological level of injury and symptomatic cardiovascular disease risk in the aging spinal injured. Spinal Cord 2001; 39: 310-317.

88 Bauman WA, Spungen AM. Risk assessment for coronary heart disease in a veteran population with spinal cord injury. Topics Spinal Cord Injury Rehabil 2007; 12: 35-53.

89 McGlinchey-Berroth R, Morrow L, Ahlquist M, Sarkarati M, Minaker KL. Late-life spinal cord injury and aging with a long term injury: characteristics of two emerging populations. J Spinal Cord Med 1995; 18: 183-193.

90 Shojaei H. Soroush MR, Modirian E. Spinal cord injury-induced osteoporosis in veterans. J Spinal Disord Tech 2006; 19: 114-117.

91 Drolet M, Noreau L, Vachon J, Moffet H. Spasticity change during and following functional rehabilitation in individuals with spinal cord injury. J Rehabil Outcomes Measure 2000; 4: 1-14.

92 Frisbie JH. Diabetes mellitus and preventable spinal cord injury. J Spinal Cord Med 2005; 28: 60-63.

93 Rajan S, McNeely MJ, Hammond M, Goldstein B, Weaver F. Association between obesity and diabetes mellitus in veterans with spinal cord injuries and disorders. Am J Phys Med Rehabil 2010; 89: 353-361.

94 Krogh K, Nielsen J, Djurhuus JC, Mosdal C, Sabroe S, Laurberg S. Colorectal function in patients with spinal cord lesions. Dis Colon Rectum 1997; 40: 1233-1239.

95 Petchkrua W, Little JW, Burns SP, Stiens SA, James JJ. Vitamin B12 deficiency in spinal cord injury: a retrospective study. J Spinal Cord Med 2003; 26: $116-121$.

96 Lazo MG, Shirazi P, Sam M, Giobbie-Hurder A, Blacconiere MJ, Muppidi M. Osteoporosis and risk of fracture in men with spinal cord injury. Spinal Cord 2001; 39: 208-214

97 Garland DE, Adkins RH, Rah A, Stewart CA. Bone loss with aging and the impact of SCl. Topics Spinal Cord Injury Rehabil 2001; 6: 47-60.

98 Bauman WA, Kirshblum S, Cirnigliaro C, Forrest GF, Spungen AM. Underestimation of bone loss of the spine with posterior-anterior dual-energy X-ray absorptiometry in patients with spinal cord injury. J Spinal Cord Med 2010; 33: 214-220.

99 Biering-Sorensen F, Bohr HH, Schaadt OP. Longitudinal study of bone mineral content in the lumbar spine, the forearm and the lower extremities after spinal cord injury. Eur J Clin Invest 1990; 20: 330-335.

100 Weaver FM, Collins EG, Kurichi J, Miskevics S, Smith B, Rajan S et al. Prevalence of obesity and high blood pressure in veterans with spinal cord injuries and disorders: a retrospective review. Am J Phys Med Rehabil 2007; 86 22-29.

101 de Groot S, Post MW, Postma K, Sluis TA, van der Woude LH. Prospective analysis of body mass index during and up to 5 years after discharge from inpatient spinal cord injury rehabilitation. J Rehabil Med 2010; 42: 922-928. 
102 Finnie AK, Buchholz AC, Martin Ginis KA. Current coronary heart disease risk assessment tools may underestimate risk in community-dwelling persons with chronic spinal cord injury. Spinal Cord 2008; 46: 608-615.

103 Dallmeijer AJ, van der Woude LH, van Kamp GJ, Hollander AP. Changes in lipid, lipoprotein and apolipoprotein profiles in persons with spinal cord injuries during the first 2 years post-injury. Spinal Cord 1999; 37: 96-102.

104 Pentland W, McColl MA, Rosenthal C. The effect of aging and duration of disability on long term health outcomes following spinal cord injury. Paraplegia 1995; 33: 367-373.

105 Smith BM, Evans CT, Kurichi JE, Weaver FM, Patel N, Burns SP. Acute respiratory tract infection visits of veterans with spinal cord injuries and disorders: rates, trends, and risk factors. J Spinal Cord Med 2007; 30: 355-361.

106 Eser P, Frotzler A, Zehnder Y, Denoth J. Fracture threshold in the femur and tibia of people with spinal cord injury as determined by peripheral quantitative computed tomography. Arch Phys Med Rehabil 2005; 86: 498-504.

107 Nelson AL, Groer S, Palacios P, Mitchell D, Sabharwal S, Kirby RL et al. Wheelchairrelated falls in veterans with spinal cord injury residing in the community: prospective cohort study. Arch Phys Med Rehabil 2010; 91: 1166-1173.

108 Slot O, Drewes A, Andreasen A, Olsson A. Erectile and ejaculatory function of males with spinal cord injury. Int Disabil Stud 1989; 11: 75-77.
109 Anderson KD, Borisoff JF, Johnson RD, Stiens SA, Elliott SL. Spinal cord injury influences psychogenic as well as physical components of female sexual ability. Spinal Cord 2007; 45: 349-359.

110 Jaovisidha S, Sartoris DJ, Martin EM, Foldes K, Szollar SM, Deftos LJ. Influence of heterotopic ossification of the hip on bone densitometry: a study in spinal cord injured patients. Spinal Cord 1998; 36: 647-653.

111 Klefbeck B, Sternhag M, Weinberg J, Levi R, Hultling C, Borg J. Obstructive sleep apneas in relation to severity of cervical spinal cord injury. Spinal Cord 1998; 36: 621-628.

112 Leduc BE, Dagher JH, Mayer P, Bellemare F, Lepage Y. Estimated prevalence of obstructive sleep apnea-hypopnea syndrome after cervical cord injury. Arch Phys Med Rehabil 2007; 88: 333-337.

113 Stinneford JG, Keshavarzian A, Nemchausky BA, Doria MI, Durkin M. Esophagitis and esophageal motor abnormalities in patients with chronic spinal cord injuries. Paraplegia 1993; 31: 384-392.

114 Yuen HK, Shotwell MS, Magruder KM, Slate EH, Salinas CF. Factors associated with oral problems among adults with spinal cord injury. J Spinal Cord Med 2009; 32: 408-415.

115 Krause JS. Self-reported problems after spinal cord injury: implications for rehabilitation practice. Topics Spinal Cord Injury Rehabil 2007; 12: 35-44. 